\title{
Review
}

\section{How apoptotic cells aid in the removal of their own cold dead bodies}

\author{
G Wickman ${ }^{1}$, L Julian ${ }^{1}$ and MF Olson ${ }^{*, 1}$
}

Apoptotic cell clearance facilitates the removal of aged, damaged, infected or dangerous cells although minimizing perturbation of surrounding tissues, and is a vital process in the development and homeostasis of multicellular organisms. Importantly, failure to correctly execute programmed cell death and subsequent corpse clearance is broadly associated with chronic inflammatory and/or autoimmune diseases such as systemic lupus erythematosus. Apoptotic cells develop dramatic morphological changes including contraction, membrane blebbing and apoptotic body formation, which were among the first and most readily identifiable features of cellular suicide. However, understanding the purpose of apoptotic cell morphological changes has proven to be elusive, and recent studies have made somewhat surprising, and occasionally opposing, conclusions about the contribution of blebbing to phagocytic clearance and prevention of inflammatory/autoimmune disease. We review the evidence indicating how apoptotic blebs actively promote corpse recognition, uptake, and generation of auto-reactive antibodies.

Cell Death and Differentiation (2012) 19, 735-742; doi:10.1038/cdd.2012.25; published online 16 March 2012

\section{Facts}

- Actomyosin contraction provides the force-driving contraction, membrane blebbing and apoptotic body formation during programmed cell death.

- Apoptotic cells display cell surface markers that facilitate recognition and uptake by phagocytic cells.

- Impaired apoptotic cell clearance may contribute to inflammation and autoimmunity.

\section{Open Questions}

- How are apoptotic cell surface markers concentrated on blebs?

- How do markers such as calreticulin and $N$-acetylglucosamine come to be displayed on the surface of apoptotic cells?

- What is the role of blebbing in the recognition and clearance of apoptotic cells?

\section{Actomyosin Contraction Drives Apoptotic Blebbing}

Apoptotic cells can often be discriminated from viable counterparts based on several morphological hallmarks including highly conspicuous nuclear condensation and fragmentation, and frequent appearance of characteristic plasma membrane blebs (Figure 1a). Blebs are balloon-like protrusive blisters formed when cellular plasma membrane delaminates from the cortical cytoskeleton, and which can be retracted and reformed in a dynamic cycling process covering the entire surface of apoptotic cells. The formation of apoptotic blebs is a physical process that results from increased hydrostatic pressure following actomyosin-mediated cellular contraction. ${ }^{1,2}$ When newly formed, blebs are devoid of actin and other cytoskeletal proteins. Subsequently, an actin cortex rapidly polymerizes within the protruding bleb, followed by the recruitment of cytoskeletal bundling proteins and myosin that then power bleb retraction. ${ }^{3}$ In apoptotic cells this cyclic process of bleb formation and retraction can occur over sustained periods, and as programmed cell death progresses blebs may become packed with cellular organelles and condensed chromatin to form the basis of fragmentary membrane-clad apoptotic bodies (Figure 1a). ${ }^{4}$ However, it should be noted that apoptotic blebbing is not a universal feature of programmed cell death, some cell types do not appear to generate membrane blebs nor undergo fragmentation. ${ }^{5}$ Nonetheless, blebbing is a very common feature of apoptotic cells and has become a morphological hallmark of programmed cell death.

In 2001, it was discovered that apoptotic blebbing is dependent upon activity of the actomyosin regulator ROCK1 kinase. $^{6,7}$ Moreover, it was apparent that apoptotic ROCK1

\footnotetext{
${ }^{1}$ Beatson Institute for Cancer Research, Glasgow G61 1BD, UK

*Corresponding author: MF Olson, Beatson Institute for Cancer Research, Garscube Estate, Switchback Road, Glasgow G61 1BD, UK. Tel: +44 (0)141 3303654 ; Fax: + 44 (0)141330 6521; E-mail: m.olson@ beatson.gla.ac.uk

Keywords: apoptosis; cytoskeleton; actin; efferocytosis

Abbreviations: ADP, adenosine diphosphate; ACAMP, apoptotic cell-associated molecular pattern; ANA, anti-nuclear antibody; DC, dendritic cell; DNA, deoxyribonucleic acid; GTP, guanosine-triphosphate; HMGB1, high-mobility group protein B1; IL-6, interleukin 6; MFG-E8, milk fat globule epidermal growth factor 8; GIcNAc, n-acetylglucosamine; PS, phosphatidylserine; SLE, systemic lupus erythematosus; TGF- $\beta$, transforming growth factor $\beta$; TMEM16F, Transmembrane protein $16 \mathrm{~F}$

Received 23.11.11; revised 08.2.12; accepted 13.2.12; Edited by G Melino; published online 16.3.12
} 

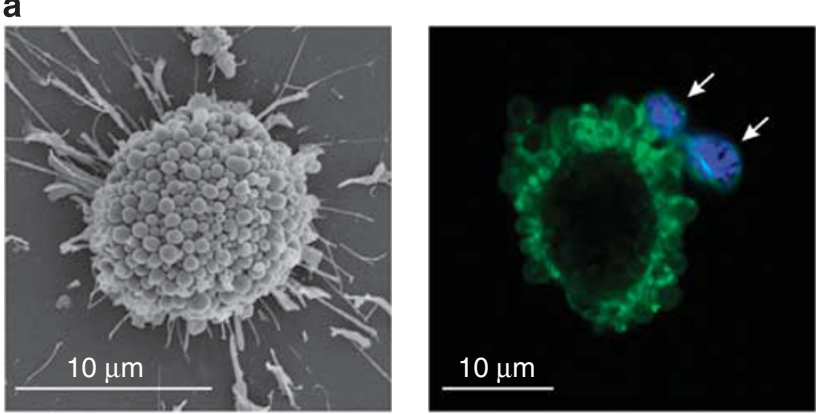

b

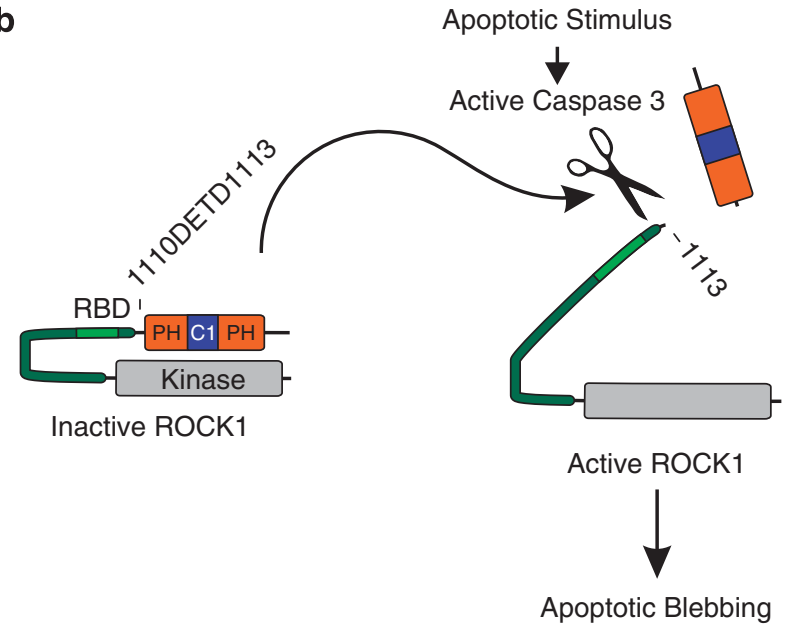

Figure 1 Apoptotic blebbing and ROCK1 cleavage. (a) Representative scanning electron micrograph of apoptotic mouse embryonic fibroblast (MEF) with many surface blebs (left panel). Representative confocal image of apoptotic MEF with multiple blebs containing condensed chromatin (right panel, white arrows). Chromatin is stained with DAPI (blue) and cellular membrane is stained with lipid dye DiO ( $\mathrm{G}=$ green). (b) Schematic of ROCK cleavage by caspase 3 at D1113. Cleavage yields a constitutively active kinase responsible for apoptotic blebbing. ${ }^{6}$ $\mathrm{RBD}$, Rho-binding domain; $\mathrm{PH}$, pleckstrin homology; $\mathrm{C}$, cysteine rich domain

activation is independent of its canonical activator Rho GTPase. This atypical form of ROCK activation was associated with caspase cleavage of ROCK1, but not ROCK2, after a conserved site within the C-terminus $\left({ }_{1110} \mathrm{DETD}_{1113}\right)^{6}$ (Figure $1 \mathrm{~b}$ ). Further investigation revealed that caspase cleavage of ROCK1 yields a constitutively active kinase fragment that is sufficient to induce membrane blebbing resembling that seen in apoptotic cells. In addition, the cleaved ROCK1 fragment appears to be important for disruption of nuclear integrity and the packaging of fragmented DNA into membrane blebs and apoptotic bodies. ${ }^{4,6}$ Thus, the generation of constitutively active ROCK1 kinase fragments appears to be an important mechanism to complete the execution phase of cellular apoptosis. When cell death has been triggered by extrinsic factors such as $T N F \alpha$, ceramide or Fas-receptor ligation, ROCK1 cleavage and activation are relatively late events, ${ }^{6,7}$ consequently ROCK inhibition does not halt the apoptotic process. ${ }^{6}$ However, in some contexts chronic or high-intensity ROCK activity may contribute to the initiation of apoptosis. Data from ROCK1 knockout mice revealed that blood pressure overload was less effective at inducing cardiomyocyte apoptosis compared with control wild-type mice, suggesting a potential role for ROCK1 activation in myocardial failure. ${ }^{8}$ Although ROCK1 cleavage and activation is associated with the formation of apoptotic blebs, and ROCK activity is necessary for blebbing, formal proof of the absolute requirement for ROCK1 cleavage as the causal event leading to apoptotic blebbing remains to be provided. Although ROCK2 is not cleaved by caspases and is therefore unlikely to be involved in apoptotic blebbing induced by conventional intrinsic and extrinsic stimuli, it can be cleaved by granzyme $\mathrm{B},{ }^{9}$ a serine protease injected into target cells by cytotoxic T-cells and natural killer cells to induce cell death by mitochondrial disruption and caspase 3 cleavage and activation. ${ }^{10}$ Interestingly, granzyme B cleaves ROCK2 analogously to caspase 3 cleavage of ROCK1; ROCK2 cleavage after D1131 releases the C-terminal autoinhibitory domain leading to constitutive kinase domain activation capable of inducing membrane blebs. ${ }^{9}$ Due to the activation of caspase 3 during granzyme B-induced apoptosis, ROCK1 cleavage also occurs, thus the relative contribution of ROCK2 cleavage towards the formation of apoptotic blebs remains unclear. Furthermore, as ROCK2 is not cleaved during apoptosis induced by conventional signals, the post-translational modification that produces constitutively active ROCK2 appears not to be generally required for apoptotic blebbing.

Although ROCK1 cleavage is apparently vital for blebbing, it seems dispensable for many other apoptotic phenomena including caspase activation, phosphatidylserine (PS) externalization, and poly ADP-ribose polymerase cleavage. ${ }^{6,7,11}$ This leaves open the question of precisely what the purpose of ROCK1 cleavage, and by extension membrane blebbing, in apoptosis might be.

\section{Apoptotic Cell Recognition}

Programmed cell death, or apoptosis, is vital for the removal of problematic or unnecessary cells in multicellular organisms. ${ }^{12,13}$ First defined in $1972,{ }^{14}$ apoptosis is an active process that ultimately concludes with the final act of cellular disposal in which phagocytic cells ingest cellular corpses and associated debris, a process termed efferocytosis. As a testament to the efficiency and rapidity of efferocytosis, it is surprisingly difficult to histologically detect apoptotic cells despite $>10^{9}$ cellular suicides occurring per day in adult tissues. ${ }^{15,16}$ There are several broadly defined phases of phagocytic clearance of apoptotic cells: (1) Find-me, characterized by the release of soluble signals that attract macrophages to the dying cell; (2) Eat-me, in which a phagocyte becomes stimulated by engaging with signals expressed on the apoptotic cell membrane; (3) Engulfment, a series of cytoskeletal modifications in the phagocyte enabling it to take up the dead cell; (4) Processing, digestion of the cellular remains through lysosomal degradation. ${ }^{17-19}$

Importantly, apoptotic cells actively participate in the initial phases by displaying significant modifications to their membranes (which can include lipids, proteins and modified carbohydrates) that are important aids to recognition and uptake. The best characterized of these externalized factors is PS, which is normally confined to the inner leaflet of the plasma membrane. ${ }^{20}$ During early apoptosis membrane 
asymmetry is lost; PS becomes externalized and serves as a major factor for apoptotic cell recognition (Figure 2a). A protein that mediates PS externalization was recently identified as the eight transmembrane spanning Transmembrane Protein 16F (TMEM16F). ${ }^{21}$ Externalized PS can be bound by milk fat globule epidermal growth factor 8 (MFG-E8), which tethers the phospolipid to integrin $\alpha_{v} \beta_{3}$ and/or $\alpha_{v} \beta_{5}$ expressed on macrophages and monocytes (Figure 2a). ${ }^{22}$ Alternatively, PS can be recognized directly by one or more receptors expressed on macrophages, including; Bai1, Tim5, and Stabilin2 (Figure 2). ${ }^{12}$ PS externalization has also been detected on viable cells in some instances, suggesting that PS exposure alone may be insufficient to trigger phagocytosis and that additional signals are necessary. ${ }^{23,24}$ In fact, enforced PS externalization induced by expression of active TMEM16F did not induce engulfment by macrophages in vitro or by dendritic cells (DCs) in vivo. ${ }^{21}$ Therefore, it has been proposed that the 'Eat-me' signal received by phagocytes must be above a threshold level to initiate efferocytosis. ${ }^{25}$ The strength of such a signal could be augmented by the binding of additional 'Eat-me' molecules, such as MFG-E8. ${ }^{11}$ Alternatively, spatial concentration of PS or other 'Eat-me' molecules on apoptotic cell membranes may also serve as phagocytic triggers that focally surpass the required threshold (discussed below). ${ }^{25}$ In addition to PS externalization, apoptotic cells have further modifications to their membrane constituents. The release and dissociation of sub-cellular membrane clad particles called apoptotic bodies results in bulk membrane loss that must be replaced from intracellular organelles such as the Golgi or endoplasmic reticulum. ${ }^{26}$ This scavenging of intracellular membranes leads to the externalization of protein and glycan groups, including calreticulin and $\mathrm{N}$-acetylglucosamine (GlcNAc), that are normally expressed only on intracellular membranes and which appear to be important for efferocytosis (Figure 2a). ${ }^{27,28}$ Externalization of GlcNAc is recognized as a determinant of apoptotic thymocyte phagocytosis while calreticulin binds complement $\mathrm{C} 1 \mathrm{q}$ and aids phagocytosis of apoptotic cells (Figure 2a). ${ }^{27,29,30}$ Moreover, many of the externalized proteins are modified by cleavage, likely by activated caspases, which might easily affect their function and/or recognition. ${ }^{31}$ The atypical externalization of intracellular material contributes to apoptotic cell-associated molecular patterns (ACAMP), which either alone or in conjunction with plasma proteins such as MFG-E8, complement $\mathrm{C} 1 \mathrm{q}$, mannose-binding lectin and surfactant protein $A$ are then recognized by macrophages to promote

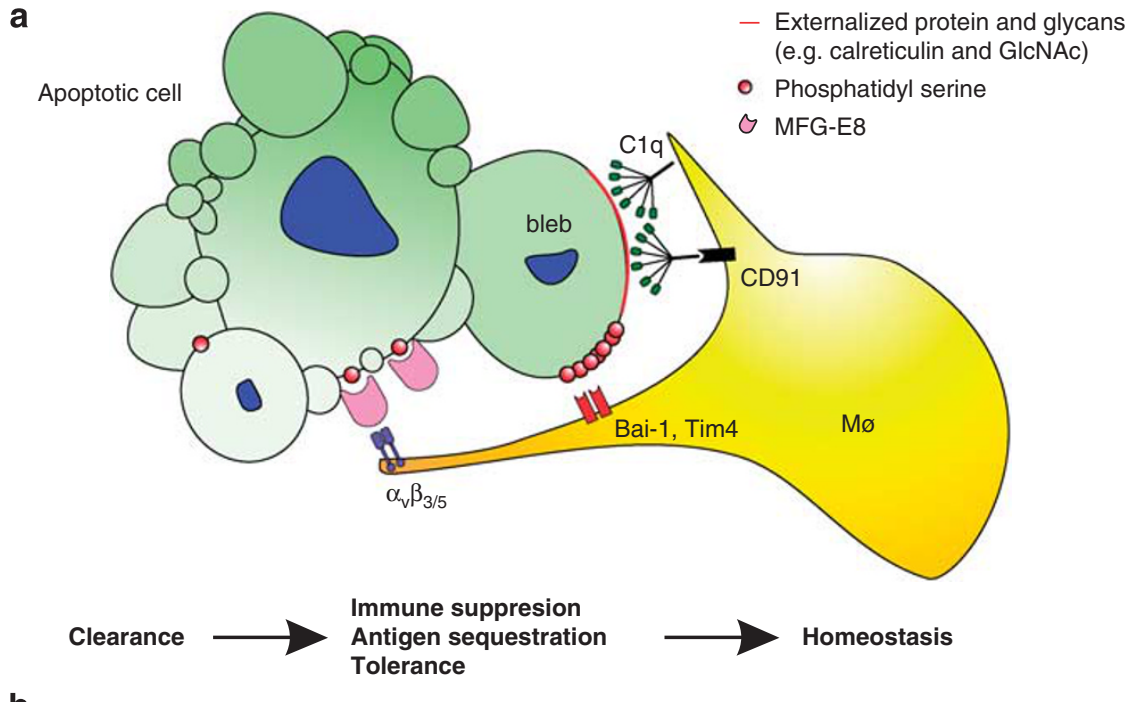

b
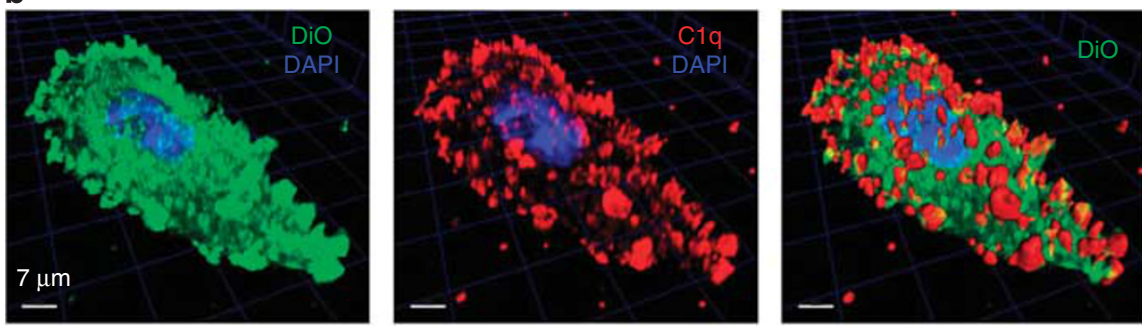

volumetic rendering of

C1q and DAPI fluorescence

Figure 2 Blebs focalize factors that promote clearance. (a) Illustration of an apoptotic cell in complex with a macrophage. Apoptotic cell (green) externalizes multiple factors including phosphatidylserine, intracellular proteins and glycan groups. These externalized factors can bind serum proteins C1q and MFG-E8. These membrane modifications enable rapid clearance by acting as 'Eat-me' signals for surveilling macrophages (Mø,yellow), thus maintaining tissue homeostasis. (b) 3 dimensional confocal reconstruction and volumetric rendering of apoptotic mouse embryonic fibroblast (MEF). Cellular membrane is stained with lipid dye DiO (green), nucleus is stained with DAPI (blue), and cell is stained with human complement C1q (red) 
clearance. ${ }^{25,29,32,33}$ The binding of a macrophage to a target apoptotic cell creates an engulfment synapse and the diverse molecular interactions between ACAMP and macrophages initiate important phases of efferocytosis, such as binding and engulfment. $^{34-36}$

\section{Apoptotic Blebbing: promoting Cell Clearance?}

A number of studies have attempted to define the role of blebbing in apoptotic clearance and revealed some potentially contradictory roles for blebs and apoptotic bodies. Several in vitro studies reported that inhibition of apoptotic blebbing significantly impaired corpse clearance by monocytes and macrophages. ${ }^{5,11,28}$ Further investigation revealed that impaired corpse clearance following defective blebbing could be rescued by the PS-bridging protein, MFG-E8. ${ }^{11}$ The implications of these studies are two-fold: firstly, apoptotic blebbing directly influences efferocytosis; and secondly, PS externalization may be a mechanism linking blebbing and phagocytosis. Although the apoptotic externalization of PS appears to be ROCK-independent, its sub-cellular localization is ROCKdependent. ${ }^{6,11}$ In fact, microscopic analysis revealed that apoptotic blebs become highly enriched for the externalized phospholipids. ${ }^{37}$ Thus, it appears that apoptotic blebs serve as focal points for accumulation of externalized PS, which is then recognized by macrophages to trigger engulfment. The possibility that apoptotic blebs provide topological context for macrophage recognition is consistent with data demonstrating PS exposure on viable cells is insufficient to trigger phagocytosis. Surprisingly, MFG-E8 failed to further enhance the in vitro phagocytic uptake of normal blebbing apoptotic cells, ${ }^{11}$ suggesting that apoptotic blebbing and subsequent PS concentration on blebs is sufficient to trigger corpse clearance in the absence of additional extracellular factors. When blebbing is impaired, efferocytosis can be rescued by bridging molecules like MFG-E8; thus there appears to be redundancy in clearance mechanisms. Such redundant compensating mechanisms may explain why several genetically modified mice with defective clearance mechanisms are neither developmentally lethal nor display severe autoimmune phenotypes (if displayed at all), as measured by survival and overall health. In addition to serving as organizational centers for PS externalization, apoptotic blebs are associated with additional membrane modifications. One of the most striking examples highlighting the potential importance of apoptotic blebs is their robust opsonization with complement $\mathrm{C} 1 \mathrm{q}$ in human endothelial cells (Figure 2b). ${ }^{38,39}$ The high-density opsonization on the surface of apoptotic blebs would be expected to efficiently trigger efferocytosis by activating specific complement receptors such as CD91 expressed by macrophages. ${ }^{29,40,41}$ Although the binding of C1q to apoptotic cells appears to be important for recognition and clearance, clearance is not dependent on further activation of the complement cascade. ${ }^{42}$ The importance of this mechanism for triggering clearance is underscored by the autoimmune disorders observed in C1q-deficient mice. ${ }^{43}$ Thus, ROCK-mediated actomyosin contraction, consequent membrane blebbing and focalized accumulation of 'Eat-me' factors might be expected to facilitate rapid efferocytosis and thus maintain self-tolerance.

\section{Apoptosis, Clearance and Autoimmunity}

The execution phase of apoptosis and subsequent corpse clearance convey powerful anti-inflammatory signals to engulfing cells and, importantly, enable apoptotic cells to remain immunologically silent. ${ }^{44-46}$ Furthermore, apoptotic cell engulfment helps induce a tolerogenic response and facilitates proteins to be appropriately recognized as 'self', thus avoiding activation of adaptive immunity towards apoptotic material. ${ }^{47}$ Collectively, the combination of rapid apoptotic cell clearance linked to suppression of immune activation allows apoptosis to proceed rapidly and efficiently with minimal collateral damage to maintain tissue homeostasis. One of the key features of apoptotic cells that allows for the rapid and stealthy removal of cellular fragments is a stable intact membrane (detectable by the exclusion of impermeable dyes such as propidium iodide) that prevents release of intracellular proteins and consequent immunological activation. ${ }^{48}$ This is in contrast to necrotic cell death, wherein cells inappropriately lyse and release their intracellular contents leading to rapid pro-inflammatory responses. ${ }^{45,49}$ Secondarily necrotic cells release 'alarmins', of which high-mobility group protein B1 (HMGB1) is the archetype, that are recognized as danger signals and provoke innate immune cells into a pro-inflammatory state (Figure 3). ${ }^{50}$ For this reason, defects in efferocytosis are believed to cause inappropriate pathological inflammation leading to the development of autoimmune diseases. Indeed, genetically modified mouse models in which genes for vital elements of cell recognition and clearance machinery such as compliment C1q or MFG-E8 have been deleted display an autoimmune phenotype resembling systemic lupus erythematosus (SLE). SLE is a chronic systemic autoimmune disease that affects multiple organ systems including joints, skin, lymph and kidneys in nearly 5 million people globally, $90 \%$ of whom are female. ${ }^{51}$ The disease is characterized by the generation of auto-reactive antibodies (particularly against nuclear antigens), the formation of antibody immune complexes and pro-inflammatory cytokine production. ${ }^{52,53}$ Animal models with defective efferocytosis develop a similar age- and sexdependent pathology as seen in human sufferers, associated with the presence of anti-nuclear antibodies (ANA), splenomegaly and glomerulonephritis. ${ }^{43,54}$ Although the pathophysiology of SLE is multifactorial, the best-defined abnormality associated with the disease is defective apoptotic cell clearance. Not only are macrophages from SLE patients deficient in autologous efferocytosis in vitro, but the number of tingible body macrophages that are responsible for the ingestion of apoptotic corpses in lymphoid tissue germinal centers are frequently reduced in SLE sufferers. ${ }^{55,56}$ Consistent with these observations, SLE is associated with elevated circulating apoptotic bodies and an accumulation of apoptotic cells in lymph node germinal centers. ${ }^{57,58}$ Furthermore, compliment C1q deficiency, which is associated with increased undigested apoptotic debris, is a potent trigger for SLE. ${ }^{59}$ The increase in free uningested apoptotic debris likely contributes to the induction of ANAs, which is a classic diagnostic feature of SLE. Overcoming self-tolerance is a pathological process closely associated with failed efferocytosis that results in immune activation towards intracellular 


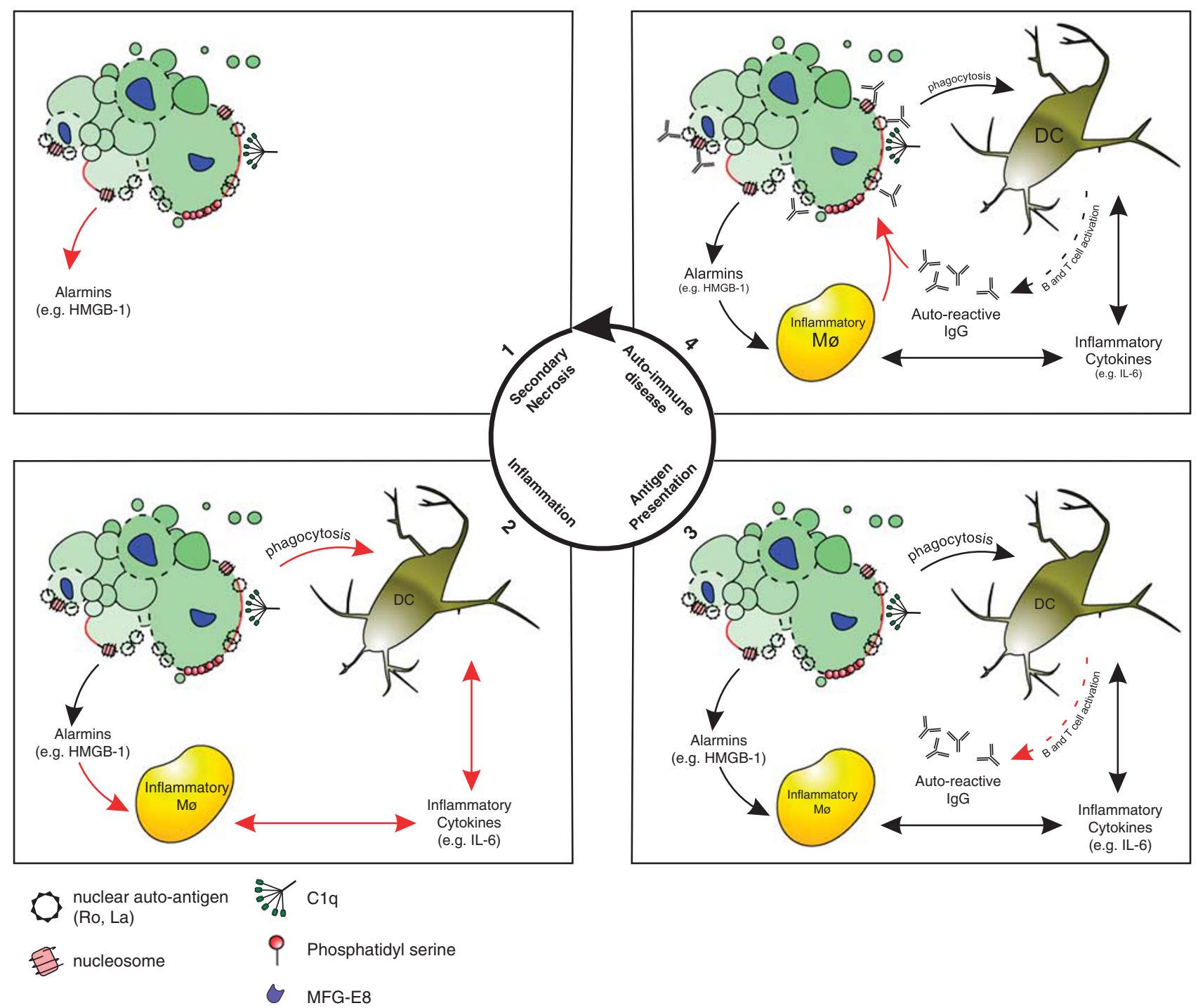

Figure 3 Schematic illustration of failed efferocytosis leading to auto-immune disease. Failure to clear apoptotic cells leads to secondary necrosis and the eventual release of alarmins such as HMGB-1 (panel 1, top left). The secondarily necrotic cell triggers the release of pro-inflammatory cytokines by HMGB-1 stimulation of macrophages (Mø) or following phagocytosis by DCs. (panel 2, bottom-left panel). In the inflammatory context, DCs present ingested apoptotic protein and express co-stimulatory molecules triggering $B$ and T-cell activation leading to the production of auto-reactive antibodies ( $\mathrm{IgG}$ (panel 3 , bottom right). Auto-reactive antibodies opsonise apoptotic cells and trigger further inflammatory responses characteristic of auto-immune disease (panel 4 , top right)

material, including nuclear proteins and DNA. Supporting this possibility, SLE-associated ANAs can be specific for novel epitopes produced only after enzymatic modifications such as caspase-mediated cleavage ${ }^{60}$ Furthermore, these autoreactive antibodies are somatically mutated IgG isotypes suggesting that they are products of B-cell affinity maturation and thus the result of an antigen-driven immune response..$^{61,62}$

The generation of self-reactive antibodies appears to be linked to phagocytosis of apoptotic debris by professional antigen-presenting DCs. ${ }^{63} \mathrm{DC}$ are potent stimulators of adaptive immune responses and in an inflammatory context present peptides generated from apoptotic proteins and potently stimulate immune responses consistent with the generation of self-reactive antibodies (Figure 3) ${ }^{64}$ In fact, the ingestion of secondarily necrotic apoptotic bodies by
DC is vital for their maturation leading to expression of co-stimulatory molecules necessary for adaptive immunity. ${ }^{64}$ These features of DC make them likely candidates to mediate auto-antibody generation following phagocytosis of apoptotic debris accumulated due to failed efferocytosis and further suggests that additional signals associated with secondary necrosis, such as HMGB1 release, are important components in the development of autoimmunity. ${ }^{65,66}$ Moreover, the ingestion of apoptotic bodies by DC can stimulate the release of pro-inflammatory cytokines, such as interleukin-6 (IL-6), thereby inducing auto- and paracrine signaling loops favoring the generation of auto-reactive antibodies. ${ }^{64,67-69}$ Once an auto-reactive antibody is produced, it would be expected to opsonize apoptotic cells and potentially encourage inappropriate inflammatory responses leading to the development 
of auto-immune/inflammatory diseases such as SLE (Figure 3). ${ }^{70}$ Although auto-immune diseases resulting from failed efferocytosis are clearly multifactorial, apoptotic blebbing appears to lie at foundational stages of disease onset.

Although apoptotic blebs certainly accumulate a collection of important 'Eat-me' factors such as PS and C1q, they also appear to be rich in auto-antigens frequently associated with autoimmune disorders such as SLE. In particular, apoptotic blebs and discrete apoptotic bodies display many nuclear auto-antigens such as DNA, nucleosomes, Ro and La (Figure 4). ${ }^{25,26,71,72}$ The implication of these observations is that blebs and apoptotic bodies are reservoirs of antigens that may contribute to the generation of auto-immune disease. ${ }^{63}$ As previously mentioned, self-tolerance can be challenged by DC uptake of apoptotic cells. Apoptotic blebbing appears to participate in this process as DC prefer smaller apoptotic body-sized cell remnants that are rich in potential autoantigens. Furthermore, the ingestion of this material can stimulate production of the pro-inflammatory cytokine IL-6 and induce DC maturation. ${ }^{64,68}$ The uptake of antigen-rich apoptotic bodies by DC coupled with the subsequent release of inflammatory mediators and cellular maturation appears to drive adaptive immunity leading to auto-immunity (Figure 4). ${ }^{64}$ Because of these observations, inhibition of apoptotic blebbing has been proposed as a potential therapy to avoid or attenuate auto-immune disease severity. ${ }^{70}$ In fact, inhibition of blebbing with the ROCK selective inhibitor Y27632 not only impaired DC phagocytosis of apoptotic bodies but completely abolished enhanced uptake following auto-antibody opsonization. ${ }^{70}$

These observations underscore the importance of apoptotic cell clearance in the maintenance of self-tolerance. However,

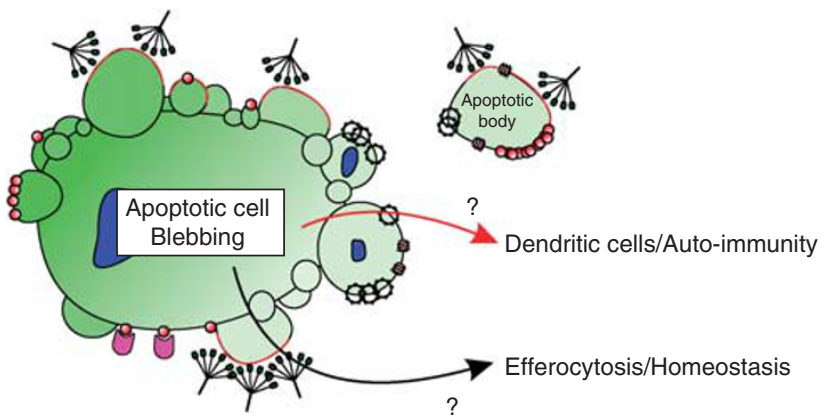

$$
\begin{aligned}
& \text { Apoptotic bleb associated molecules } \\
& \text { - C1q receptors (e.g. calreticulin) } \\
& \text { ₹ C1q } \\
& \text { १ PS } \\
& \text { \& MFG-E8 } \\
& \text { - Nuclear auto-antigen (e.g. Ro and La) } \\
& \text { Nucleosome }
\end{aligned}
$$

Figure 4 Apoptotic blebs are repositories of membrane modifications. Illustration of apoptotic cell with numerous blebs concentrating 'Eat-me' signals as well as nuclear auto-antigens. The relative importance of apoptotic blebs for efficient efferocytosis and consequent maintenance of homeostasis versus the presentation of nuclear autoantigens to DCs leading to the development of autoimmunity is unclear, and likely awaits the development of in vivo models deficient in apoptotic blebbing it is important to note that apoptotic clearance failure in itself may be insufficient to promote auto-immune disease; in fact, mannose-binding lectin-deficient mice have demonstrated apoptotic clearance defects without autoimmunity. ${ }^{73}$ This suggests that determinants, in addition to clearance, participate in the immunological processing of apoptotic cell debris. It has been proposed that immunosuppressive transforming growth factor $\beta$ (TGF- $\beta$ ) release stimulated by binding of apoptotic cells to macrophages may be sufficient to avoid potentially problematic auto-antibody generation, even in the absence of clearance. ${ }^{16}$ Nonetheless, defective cell clearance, resulting from impairment or elimination of the myriad components of efferocytosis, is undoubtedly linked to autoimmune disease as well as several other disorders in human and mice including atherosclerosis, neuropathy, arthritis, and anemia. $^{12,74}$

Collectively, these studies indicate that apoptotic blebbing, as a mechanism to promote cell clearance, is a double-edged sword. Although blebs appear to be important for rapid uptake and clearance to maintain homeostasis, simultaneously they also are sources of auto-antigens (Figure 4). It appears that the same material recognized by macrophages to trigger clearance may also be recognized by other cell types, such as DCs, to generate auto-immune antibodies. The mechanisms that may lead to these opposing outcomes is currently unclear; however, defects in macrophage uptake or increases in apoptosis appear to be important determinants. Hypothetically, the accumulation of apoptotic debris would likely lead to increased probability of DC activation and, over time, this inappropriate activation would overcome self-tolerance and lead to the generation of auto-reactive antibodies characteristic of autoimmunity. Although the linkage between apoptotic blebbing and autoimmune disease has been inferred, there has been no definitive demonstration of the importance of apoptotic blebbing in vivo. To date, studies investigating apoptotic blebbing in the context of clearance and auto-immune disease have been largely limited to in vitro experimentation that cannot recapitulate the complexity of interactions between apoptotic cells and their environment. Furthermore, these studies may also be compromised by certain aspects of their experimental design that could affect outcomes in subsequent assays, such as their dependence on chemical inhibitors to interfere with apoptotic blebbing, and extensive washing steps that might alter the stability and structure of the apoptotic cells. As a result, many of the observations from in vitro studies regarding the possible influence of blebbing towards apoptotic cell clearance and consequently on the development of autoimmune disease are potentially compromised. Ultimately clear determination of the role that apoptotic blebs have in cell clearance and/or the generation of autoimmune disease will require an in vivo model of defective blebbing.

\section{Conflict of Interest}

The authors declare no conflict of interest.

Acknowledgements. Work in the Molecular Cell Biology laboratory of the Beatson Institute for Cancer Research is supported by Cancer Research UK. 
1. Charras GT, Coughlin M, Mitchison TJ, Mahadevan L. Life and Times of a Cellular Bleb. Biophys J 2008; 94: 1836-1853.

2. Charras GT, Yarrow JC, Horton MA, Mahadevan L, Mitchison TJ. Non-equilibration of hydrostatic pressure in blebbing cells. Nature 2005; 435: 365-369.

3. Charras GT, Hu CK, Coughlin M, Mitchison TJ. Reassembly of contractile actin cortex in cell blebs. J Cell Biol 2006; 175: 477-490.

4. Croft DR, Coleman ML, Li S, Robertson D, Sullivan T, Stewart CL et al. Actin-myosinbased contraction is responsible for apoptotic nuclear disintegration. J Cell Biol 2005; 168 245-255.

5. Orlando KA, Stone NL, Pittman RN. Rho kinase regulates fragmentation and phagocytosis of apoptotic cells. Exp Cell Res 2006; 312: 5-15.

6. Coleman ML, Sahai EA, Yeo M, Bosch M, Dewar A, Olson MF. Membrane blebbing during apoptosis results from caspase-mediated activation of ROCK I. Nat Cell Biol 2001 3: 339-345.

7. Sebbagh M, Renvoize C, Hamelin J, Riche N, Bertoglio J, Breard J. Caspase-3-mediated cleavage of ROCK I induces MLC phosphorylation and apoptotic membrane blebbing. Nat Cell Biol 2001; 3: 346-352.

8. Chang J, Xie M, Shah VR, Schneider MD, Entman ML, Wei L et al. Activation of Rho-associated coiled-coil protein kinase 1 (ROCK-1) by caspase-3 cleavage plays an essential role in cardiac myocyte apoptosis. Proc Natl Acad Sci USA 2006; 103 14495-14500.

9. Sebbagh M, Hamelin J, Bertoglio J, Solary E, Breard J. Direct cleavage of II ROCK by granzyme $B$ induces target cell membrane blebbing in a caspase-independent manner. $J$ Exp Med 2005; 201: 465-471.

10. Perl M, Denk S, Kalbitz M, Huber-Lang M. Granzyme B: a new crossroad of complement and apoptosis. Adv Exp Med Biol 2012; 946: 135-146.

11. Witasp E, Uthaisang W, Elenstrom-Magnusson C, Hanayama R, Tanaka M, Nagata S et al. Bridge over troubled water: milk fat globule epidermal growth factor 8 promotes human monocyte-derived macrophage clearance of non-blebbing phosphatidylserine-positive target cells. Cell Death Diff 2007; 14: 1063-1065.

12. Elliott MR, Ravichandran KS. Clearance of apoptotic cells: implications in health and disease. J Cell Biol 2010; 189: 1059-1070.

13. Baehrecke EH. How death shapes life during development. Nat Rev Mol Cell Biol 2002; 3 : 779-787.

14. Kerr JF, Wyllie AH, Currie AR. Apoptosis: a basic biological phenomenon with wide-ranging implications in tissue kinetics. Br J Cancer 1972; 26: 239-257.

15. Mochizuki H, Goto K Mori H, Mizuno Y. Histochemical detection of apoptosis in Parkinson's disease. J Neurol Sci 1996; 137: 120-123.

16. Erwig L-P, Henson PM. Immunological consequences of apoptotic cell phagocytosis. Am J Path 2007; 171: 2-8.

17. Erwig LP, McPhilips KA, Wynes MW, Ivetic A, Ridley AJ, Henson PM. Differentia regulation of phagosome maturation in macrophages and dendritic cells mediated by $R$ ho GTPases and ezrin-radixin-moesin (ERM) proteins. Proc Natl Acad Sci USA 2006; 103 12825-12830.

18. Kinchen JM, Doukoumetzidis K, Almendinger J, Stergiou L, Tosello-Trampont A, Sifri CD et al. A pathway for phagosome maturation during engulfment of apoptotic cells. Nat Cell Biol 2008; 10: 556-566.

19. Kinchen JM, Ravichandran KS. Identification of two evolutionarily conserved genes regulating processing of engulfed apoptotic cells. Nature 2010; 464: 778-782.

20. Verhoven B, Schlegel RA, Williamson P. Mechanisms of phosphatidylserine exposure, a phagocyte recognition signal, on apoptotic T lymphocytes. J Exp Med 1995; 182: 1597-1601.

21. Segawa K, Suzuki J, Nagata S. Constitutive exposure of phosphatidylserine on viable cells Proc Natl Acad Sci USA 2011; 108: 19246-19251.

22. Hanayama R, Tanaka M, Miwa K, Shinohara A, Iwamatsu A, Nagata S. Identification of factor that links apoptotic cells to phagocytes. Nature 2002; 417: 182-187.

23. Dillon SR, Mancini M, Rosen A, Schlissel MS. Annexin V binds to viable B cells and colocalizes with a marker of lipid rafts upon B cell receptor activation. J Immunol 2000 164: 1322-1332.

24. van den Eijnde SM, van den Hoff MJ, Reutelingsperger $C P$, van Heerde WL, Henfling ME, Vermeii-Keers $\mathrm{C}$ et al. Transient expression of phosphatidylserine at cell-cell contact areas is required for myotube formation. J Cell Sci 2001; 114 (Part 20): 3631-3642.

25. Fadeel B. Plasma membrane alterations during apoptosis: role in corpse clearance. Antioxid Redox Signal 2004; 6: 269-275.

26. Franz S, Herrmann K, Furnrohr BG, Sheriff A, Frey B, Gaipl US et al. After shrinkage apoptotic cells expose internal membrane-derived epitopes on their plasma membranes. Cell Death Diff 2007; 14: 733-742.

27. Paidassi H, Tacnet-Delorme P, Verneret M, Gaboriaud C, Houen G, Duus K et al. Investigations on the $\mathrm{C} 1 \mathrm{q}$-calreticulin-phosphatidylserine interactions yield new insights into apoptotic cell recognition. J Mol Biol 2011; 408: 277-290.

28. Orlando KA, Pittman RN. Rho kinase regulates phagocytosis, surface expression of GlcNAc, and Golgi fragmentation of apoptotic PC12 cells. Exp Cell Res 2006; 312 3298-3311.

29. Ogden CA, deCathelineau A, Hoffmann PR, Bratton D, Ghebrehiwet B, Fadok VA et al. C1q and mannose binding lectin engagement of cell surface calreticulin and CD9 initiates macropinocytosis and uptake of apoptotic cells. J Exp Med 2001; 194 $781-795$
30. Duvall $\mathrm{E}$, Wyllie AH, Morris RG. Macrophage recognition of cells undergoing programmed cell death (apoptosis). Immunology 1985; 56: 351-358

31. Hengartner MO. The biochemistry of apoptosis. Nature 2000; 407: 770-776.

32. Gregory CD. CD14-dependent clearance of apoptotic cells: relevance to the immune system. Curr Opin Immunol 2000; 12: 27-34.

33. Schagat TL, Wofford JA, Wright JR. Surfactant protein A enhances alveolar macrophage phagocytosis of apoptotic neutrophils. J Immunol 2001; 166: 2727-2733.

34. Erwig LP, Henson PM. Clearance of apoptotic cells by phagocytes. Cell Death Diff 2008; 15: $243-250$

35. Grimsley C, Ravichandran KS. Cues for apoptotic cell engulfment: eat-me, don't eat-me and come-get-me signals. Trends Cell Biol 2003; 13: 648-656.

36. Hoffmann PR, deCathelineau AM, Ogden CA, Leverrier Y, Bratton DL, Daleke DL et al. Phosphatidylserine (PS) induces PS receptor-mediated macropinocytosis and promotes clearance of apoptotic cells. J Cell Biol 2001; 155: 649-659.

37. Pace KE, Lee C, Stewart PL, Baum LG. Restricted receptor segregation into membrane microdomains occurs on human T cells during apoptosis induced by galectin-1. J Immuno 1999; 163: 3801-3811.

38. Korb LC, Ahearn JM. C1q binds directly and specifically to surface blebs of apoptotic human keratinocytes: complement deficiency and systemic lupus erythematosus revisited. J Immunol 1997; 158: 4525-4528.

39. Navratil JS, Watkins SC, Wisnieski JJ, Ahearn JM. The globular heads of C1q specifically recognize surface blebs of apoptotic vascular endothelial cells. J Immunol 2001; 166: $3231-3239$.

40. Mevorach D, Mascarenhas JO, Gershov D, Elkon KB. Complement-dependent clearance of apoptotic cells by human macrophages. J Exp Med 1998; 188: 2313-2320.

41. Gaipl US, Kuenkele S, Voll RE, Beyer TD, Kolowos W, Heyder P et al. Complement binding is an early feature of necrotic and a rather late event during apoptotic cell death. Cell Death Differ 2001; 8: 327-334.

42. Lu JH, Teh BK, Wang L, Wang YN, Tan YS, Lai MC et al. The classical and regulatory functions of $\mathrm{C} 1 \mathrm{q}$ in immunity and autoimmunity. Cell Mol Immunol 2008; 5: 9-21.

43. Botto M, Dell' Agnola C, Bygrave A, Thompson EM, Cook HT, Petry F et al. Homozygous C1q deficiency causes glomerulonephritis associated with multiple apoptotic bodies. Nat Genet 1998; 19: 56-59.

44. Meagher LC, Savill JS, Baker A, Fuller RW, Haslett C. Phagocytosis of apoptotic neutrophils does not induce macrophage release of thromboxane B2. J Leukoc Biol 1992; 52: 269-273.

45. Stern M, Savill J, Haslett C. Human monocyte-derived macrophage phagocytosis of senescent eosinophils undergoing apoptosis. Mediation by alpha $v$ beta $3 / C D 36 /$ thrombospondin recognition mechanism and lack of phlogistic response. Am J Pathol 1996; 149: 911-921.

46. Voll RE, Herrmann M, Roth EA, Stach C, Kalden JR, Girkontaite I. Immunosuppressive effects of apoptotic cells. Nature 1997; 390: 350-351.

47. Poon IKH, Hulett MD, Parish CR. Molecular mechanisms of late apoptotic/necrotic cell clearance. Cell Death Diff 2010; 17: 381-397.

48. Overbeeke R, Steffens-Nakken H, Vermes I, Reutelingsperger C, Haanen C. Early features of apoptosis detected by four different flow cytometry assays. Apoptosis 1998; 3: 115-121.

49. Savill J, Fadok V, Henson P, Haslett C. Phagocyte recognition of cells undergoing apoptosis. Immunol Today 1993; 14: 131-136.

50. Lotze MT, Tracey KJ. High-mobility group box 1 protein (HMGB1): nuclear weapon in the immune arsenal. Nat Rev Immunol 2005; 5: 331-342.

51. Whitacre CC. Sex differences in autoimmune disease. Nature Immunol 2001; 2: 777-780.

52. Gigante A, Gasperini ML, Afeltra A, Barbano B, Margiotta D, Cianci R et al. Cytokines expression in SLE nephritis. Eur Rev Med Pharmacol Sci 2011; 15: 15-24.

53. Van Bruggen $\mathrm{MC}$, Kramers $\mathrm{C}$, Berden JH. Autoimmunity against nucleosomes and lupus nephritis. Ann Med Interne 1996; 147: 485-489.

54. Hanayama R, Tanaka M, Miyasaka K, Aozasa K, Koike M, Uchiyama Y et al. Autoimmune disease and impaired uptake of apoptotic cells in MFG-E8-deficient mice. Science 2004; 304: 1147-1150.

55. Herrmann M, Voll RE, Zoller OM, Hagenhofer M, Ponner BB, Kalden JR. Impaired phagocytosis of apoptotic cell material by monocyte-derived macrophages from patients with systemic lupus erythematosus. Arthritis Rheum 1998; 41: 1241-1250.

56. Baumann I, Kolowos W, Voll RE, Manger B, Gaipl U, Neuhuber WL et al. Impaired uptake of apoptotic cells into tingible body macrophages in germinal centers of patients with systemic lupus erythematosus. Arthritis Rheum 2002; 46: 191-201.

57. Gaipl US, Munoz LE, Grossmayer G, Lauber K, Franz S, Sarter K et al. Clearance deficiency and systemic lupus erythematosus (SLE). J Autoimmun 2007; 28: 114-121

58. Perniok A, Wedekind F, Herrmann M, Specker C, Schneider M. High levels of circulating early apoptic peripheral blood mononuclear cells in systemic lupus erythematosus. Lupus 1998; 7: 113-118.

59. Bowness P, Davies KA, Norsworthy PJ, Athanassiou P, Taylor-Wiedeman J, Borysiewicz LK et al. Hereditary C1q deficiency and systemic lupus erythematosus. QJM 1994; 87: 455-464.

60. Casiano CA, Ochs RL, Tan EM. Distinct cleavage products of nuclear proteins in apoptosis and necrosis revealed by autoantibody probes. Cell Death Differ 1998; 5 : 183-190. 
61. Radic MZ, Weigert M. Genetic and structural evidence for antigen selection of anti-DNA antibodies. Annu Rev Immunol 1994; 12: 487-520.

62. Winkler $\mathrm{TH}$, Fehr $\mathrm{H}$, Kalden JR. Analysis of immunoglobulin variable region genes from human IgG anti-DNA hybridomas. Eur J Immunol 1992; 22: 1719-1728.

63. Fransen JH, van der Vlag J, Ruben J, Adema GJ, Berden JH, Hilbrands LB. The role of dendritic cells in the pathogenesis of systemic lupus erythematosus. Arthritis Res Ther 2010; 12: 207.

64. Fransen JH, Hilbrands LB, Ruben J, Stoffels M, Adema GJ, van der Vlag J et al. Mouse dendritic cells matured by ingestion of apoptotic blebs induce $T$ cells to produce interleukin17. Arthrit Rheumat 2009; 60: 2304-2313.

65. Sauter B, Albert ML, Francisco L, Larsson M, Somersan S, Bhardwaj N. Consequences of cell death: exposure to necrotic tumor cells, but not primary tissue cells or apoptotic cells, induces the maturation of immunostimulatory dendritic cells. J Exp Med 2000; 191: 423-434.

66. Steinman RM, Turley S, Mellman I, Inaba K. The induction of tolerance by dendritic cells that have captured apoptotic cells. J Exp Med 2000; 191: 411-416.

67. Urbonaviciute V, Furnrohr BG, Meister S, Munoz L, Heyder P, De Marchis F et al. Induction of inflammatory and immune responses by HMGB1-nucleosome complexes: implications for the pathogenesis of SLE. J Exp Med 2008; 205: 3007-3018.

68. Fransen JH, Hilbrands LB, Jacobs CW, Adema GJ, Berden JH, Van der Vlag J. Both early and late apoptotic blebs are taken up by DC and induce IL-6 production. Autoimmunity 2009; 42: 325-327.

69. Suber T, Rosen A. Apoptotic cell blebs: repositories of autoantigens and contributors to immune context. Arthrit Rheumat 2009; 60: 2216-2219.
70. Frisoni L, McPhie L, Colonna L, Sriram U, Monestier M, Gallucci S et al. Nuclea autoantigen translocation and autoantibody opsonization lead to increased dendritic cell phagocytosis and presentation of nuclear antigens: a novel pathogenic pathway for autoimmunity? J Immunol 2005; 175: 2692-2701.

71. Casciola-Rosen LA, Anhalt G, Rosen A. Autoantigens targeted in systemic lupus erythematosus are clustered in two populations of surface structures on apoptotic keratinocytes. J Exp Med 1994; 179: 1317-1330.

72. Schiller M, Bekeredjian-Ding I, Heyder P, Blank N, Ho AD, Lorenz HM. Autoantigens are translocated into small apoptotic bodies during early stages of apoptosis. Cell Death Diff 2008; 15: 183-191.

73. Stuart LM, Takahashi K, Shi L, Savill J, Ezekowitz RA. Mannose-binding lectin-deficient mice display defective apoptotic cell clearance but no autoimmune phenotype. $\mathrm{J}$ Immunol 2005; 174: 3220-3226.

74. Nagata S, Hanayama R, Kawane K. Autoimmunity and the clearance of dead cells. Cell 2010; 140: 619-630.

This work is licensed under the Creative Commons Attribution-NonCommercial-No Derivative Works 3.0

Unported License. To view a copy of this license, visit http:// creativecommons.org/licenses/by-nc-nd/3.0 